\title{
ENTREPRENEURSHIP IN THE SYSTEM OF RESOURCES FOR THE URBAN AGGLOMERATION DEVELOPMENT: THE CASE OF KRASNODAR CITY AGGLOMERATION
}

\author{
Alexey KOLBA ${ }^{1}$, Maria TERESHINA ${ }^{2}$ \\ ${ }^{1,2}$ Federal State Budgetary Educational Institution of Higher Education «Kuban State \\ University», Krasnodar, Russia \\ Corresponding author e-mail: mwstepanova@mail.ru
}

\begin{abstract}
Entrepreneurs, as a rule, are one of the significant subjects in the urban agglomeration development. Agglomeration effects create new business opportunities. However, analysis of specific situations does not always confirm these theoretical provisions. The results of the study conducted by the authors in the form of an expert survey to identify the problems and resources of the development of Krasnodar city agglomeration show that the development business is the most active participant and stakeholder in this project. At the same time, companies operating in this area prefer not to take their interests into the public space, but to implement them as part of lobbying activities at the level of regional authorities and municipalities. The interests of entrepreneurs representing other sectors of the economy are latent, and entrepreneurs, being potential beneficiaries of the systemic agglomeration development project, at this stage do not act as an independent entity. Opportunities and risks for most entrepreneurial structures (primarily small and medium-sized businesses) are not aggregated and articulated, which does not allow them to become a driver of agglomeration processes.
\end{abstract}

Keywords: Krasnodar city agglomeration, Entrepreneurship, Business, Development, Public policy, Lobbying.

JEL Classification: O18; R12

\section{INTRODUCTION}

Business, both big, for example, the largest retailers, as well as small and mediumsized enterprises, is traditionally considered as one of the significant subjects of the development of urban agglomerations and, at the same time, as one of the main stakeholders of agglomeration projects. Numerous studies conceptualize concentration processes of various types of entrepreneurial activity as a result of the business gravitation towards the cores of agglomerations generating capacious sales markets (Minakir, 2019). Entrepreneurs' interest in the development of agglomerations in general is associated with minimizing costs, as well as achieving positive effects of external (Marshall, 1984) and internal (Krugman, 1991) economies of scale. Researchers interpret agglomerations as poles of economic growth, generation of innovations (Liming Chen, 2021) and entrepreneurial activity. The indicators of the number of small and medium-sized businesses per population are one of the key 
indicators for a number of methods for assessing the development of agglomerations (Puzanov, 2017).

At the same time, the role of entrepreneurial structures as a participant in the processes of modeling and managing the growth of agglomerations has not been sufficiently studied to date. This problem is also relevant for Krasnodar urban agglomeration, on the materials of which we carried out this study.

The authors assume that as Krasnodar agglomeration goes through various development stages, as well as new types of interactions between the main stakeholders (including proactive budgeting), the relationship between government and business will be subject to new challenges and open up new opportunities. The issues of empowering business in decision-making for agglomeration development, the search for effective tools for cooperation and coordination, ways and means of aligning interests involved in co-managing actors require empirical analysis and theoretical justification. The object of this study is the potential of business structures in the sustainable development of the Krasnodar agglomeration

\section{THEORETICAL FOUNDATIONS AND METHODOLOGICAL APPROACHES OF THE STUDY}

Stone (Stone, 1989), laid the foundation for the urban regime theory, for the first time defining the role of big business as a participant in "systemic power" to improve the efficiency of urban governance and the formation of its coalition character. This theory formed the basis for a number of research directions in the field of determining the mechanisms of inclusiveness, participation and subsidiarity of business (large, medium and small) as a resource for the development of cities and urban agglomerations (Peters, 2012; Mossberger, 2001).

Most modern research uses the model of urban co-management as a model of sustainable management of urban agglomerations' development, which determines the shift in focus from urban management to urban governance (Edelendos, 2018; Pierry, 1999). This approach is focused on multi-level management, the formation of effective networks of cooperation and the synergistic effect of the participation of various actors (including business representatives) in solving the problems of agglomeration development. The ability of governing bodies and businesses to set collective goals and achieve them, as well as create rules shared by the main stakeholders, makes it possible to respond to modern challenges more effectively (Deng, 2018; Connolly, 2020).

At the same time, despite the growing popularity of the urban co-governance model, the role of business and its readiness for appropriate transformations is rather controversial. There are more and more research questions related to the problem of consolidating multidirectional business interests, the formation of an effective model of cooperation and collaborative algorithms that allow achieving sustainable results, etc. In the Russian scientific discourse, only a few studies are devoted to this issue, considering mainly theoretical problems (Korotkova, 2016; Titov, 2021).

The neoinstitutional approach is the basis of this research. This approach considers the interactions of the actors of political and administrative management as derivatives of the existing rules and regulations of relations, predetermined by the nature of their institutionalization (North). From the point of view of this approach, the process of identifying and overcoming the problems of agglomeration development is mediated 
by the current configuration of interests of political and administrative structures and related interest groups. In this context, the direction and nature of the use of political and administrative resources primarily depends on the extent to which the existing institutions of management allow to consolidate and take into account the opinions of the main subjects of development when making decisions.

\section{RESEARCH METHODS}

The authors chose the expert survey method as the main research method. This made it possible to identify and aggregate the opinions of specialists directly involved in the development of Krasnodar urban agglomeration.

The authors studied the following blocks of questions in the framework of the expert survey "Problems and resources for the development of Krasnodar urban agglomeration" conducted in April-June 2021:

- Choosing a model for managing the agglomeration.

- Establishment of the boundaries of the agglomeration.

- Problems, subjects, resources for the development of the agglomeration.

- Conflicts in the agglomeration development.

- Scenarios for the agglomeration development.

One of the key research questions was to identify the role of business in solving the problems of the development of the agglomeration, the influence on the choice of a model for managing it, and the settlement of emerging conflicts.

The authors interviewed 16 experts representing the scientific community, government bodies, public structures, and the business community. Based on the results of empirical research, the authors made a number of generalizations and conclusions.

The authors also used the analysis of regulatory documents and statistical data to characterize the development of entrepreneurship as a resource an agglomeration development.

\section{RESULTS}

Krasnodar urban agglomeration has evolved spontaneously for many years and is currently at the initial stage of its development. The following factors were decisive for the agglomeration processes: the administrative status of the regional center - makes it possible to obtain economic rent due to the effect of "capitalism" and the attractiveness of urban space for business and the population; intensive inter-municipal exchanges in the activities of industrial and commercial enterprises; daily commuting from suburbs to the regional a center for educational and labor purposes; large-scale residential development of suburban areas and traditionally high entrepreneurial activity for the South of Russia, contributing to the concentration of places for the employment of labor and the location of production.

The institutionalization of Krasnodar urban agglomeration is associated with three main documents: Strategy of socio-economic development of Krasnodar region until 2030 (Legislative Assembly of the Krasnodar Territory, 2018), Spatial development strategy of the Russian Federation for the period up to 2025 (Government of the Russian Federation, 2019) and Strategy of socio-economic development of the municipality of the city of Krasnodar until 2030 (The city Duma of Krasnodar, 2021). These documents 
consider Krasnodar urban agglomeration as an important element of economic zoning and a territory with a diversified innovative economy, rational places of employment, a harmonious environment for business development, a promising large center of economic growth in the Russian Federation, capable of providing a significant contribution to the country's economic growth.

The structure of the economy of Krasnodar urban agglomeration is specific. In the basic industries, the largest share is occupied by retail trade (over 45\%), industry (about 40\%), construction (about 8\%) and transport (about 6\%). In addition, the traditional industries that have somewhat reduced their importance in recent years are agriculture and the resort and tourist complex. Manufacturing as a whole is characterized by low added value and insufficient development of "creative industries". At the same time, the leader in terms of key economic characteristics is the trade, transport and logistics complex. A total of 45,356 legal entities and 52,670 individual entrepreneurs are registered in Krasnodar. The development of an agglomeration provides obvious advantages and opportunities for business development, since potential consumers with better paying capacity are concentrated in a limited area, and the population has a demand for a more diverse range of products and services.

According to forecast models, the population of Krasnodar will reach 3 million 200 thousand people by 2040, and in the core of the agglomeration - 2 million 100 thousand. At the same time, the pace of housing construction outstrips the pace of infrastructure construction, and the density of the road network and green public spaces does not meet the standards.

The first agglomeration belt includes Novotitarovskaya, Dinskaya, Goryachy Klyuch, Severskaya and Vasyurinskaya as basic agglomeration centers. At the same time, several municipalities located on the territory of the Republic of Adygea historically gravitate towards Krasnodar. Their location objectively creates a number of advantages in development (proximity to the center of the agglomeration and the availability of free land, relatively cheap labor and housing, etc.), which is confirmed by the accelerated rates of economic growth of these territories in the last decade. The construction of a bridge across the Kuban River, connecting Krasnodar and the Republic of Adygea promoted a new vision of Krasnodar agglomeration development in the field of economic and infrastructural processes of spatial development.

Determining the strategic vision for development and the main points of growth of Krasnodar urban agglomeration is an important factor that can consolidate business interests and create incentives for entrepreneurs to participate in co-management. An attempt to implement this plan is seen in the project for the development of the northeastern part of Krasnodar. On an area of 2.2 thousand hectares, it is planned to build a new residential neighborhood with social facilities and infrastructure for the residence of about 187 thousand people. An advanced medical cluster will also be built there as well as a multimodal transport hub in the immediate vicinity of the district. Such projects can become an effective tool for attracting investments and developing publicprivate partnerships. In general, experts believe that in order to create an agglomeration effect, Krasnodar needs a megaproject that would attract not only private, but also public investment to the city.

Systemic problems are associated with the growing imbalance of investments in new housing construction and modernization of the old buildings. Experts emphasize the need to build transparent and open relationships between public authorities, business, housing and communal services and the population. 
The strengths of the entrepreneurial and investment sector for the development of Krasnodar urban agglomeration include:

- active promotion of the investment potential of the city, as a result of which the city of Krasnodar is the leader in attracted investments in the south of Russia;

- state support for investors (subsidies, tax incentives, project support);

- a rapidly growing population, a correspondingly growing sales market and a high capacity of the labor market;

- synergistic effect of agglomeration: all other things being equal, agglomeration is more attractive for investments.

Weaknesses include:

- weak diversification of Krasnodar investment portfolio: the main investors are several companies representing one area - housing construction. Manufacturing industries (including the food industry), as well as other high-tech industries in the investment portfolio are not fully represented;

- insufficient use of such instruments as land tax relief, land rent;

- underutilization of the potential of municipal-private and public-private partnerships;

- insufficient efficiency of involvement in the economic turnover of municipal property;

- shortage of sites fully prepared for the implementation of investment projects;

- infrastructural constraints - the quality of engineering and road infrastructure;

- lack of qualified personnel for promising investment projects.

Successful practices aimed at creating incentives for business development within an agglomeration include:

- availability of an approved investment strategy;

- availability of well-developed legislation on the protection of investors' rights and mechanisms for supporting investment activities;

- the presence of an institutional structure - the Council for Improving the Investment Climate;

- availability of infrastructure for the placement of production and other facilities of investors;

- creation of a unified regulation for support of investment projects on the principle of "one window";

- formation of channels of direct communication between investors and city authorities for the prompt solution of problems and issues arising in the process of investment activities.

At the same time, it should be noted that these mechanisms are institutionalized within the city of Krasnodar and are not actually included in the development of the agglomeration as a whole.

Despite the approval of the agglomeration model for the development of the city of Krasnodar, chosen in 2019, experts point to a number of problems in its implementation. These include: lack of a clear understanding of how and in what time frame this model will be implemented; postponement for an indefinite period of the conclusion of an interregional agreement on the development of the agglomeration, the relatively weak interest of municipal and regional authorities in the creation of common governance structures (the lack of interest of Adygea side is especially emphasized). 
Also, so far there is little interest from business (with the exception of developer) in this project.

The real estate developers primarily source the lands directly adjacent to the metropolitan area of this agglomeration. Disproportionate development of Krasnodar on the right bank of the Kuban River leads to large-scale development of free spaces in the eastern, northern and western zones and the construction of new multi-storey and cottage commuter towns. The expansion of the commuter towns actually connects the city with the industrial suburbs and satellite settlements, between which there were large spaces of inter-settlement territory.

One of the important development problems that impede the organizational design of an agglomeration is the uncertainty with the choice of its management model. Most experts are inclined to believe that it is necessary to preserve the existing municipalities. At the same time, some emphasize the possibility of creating a single one-tier or twotier municipality. It should be noted that at present such a combination of municipalities belonging to different constituent entities of the Russian Federation is prohibited by Russian legislation. The best option may be to manage the agglomeration on the basis of inter-municipal agreements, which should be preceded by an agreement between the regions (Krasnodar Krai and the Republic of Adygea).

Business representatives are one of the target groups interested in implementing an agglomeration development project. At the same time, experts note that due to more favorable conditions, namely, low rental rates, businesses are more actively building up land within the Republic of Adygea. This, in turn, causes contradictions between municipalities. This state of affairs can become a serious obstacle to the further development of the project.

Most experts consider the key stakeholders of the project to be large companies with good inter-municipal and inter-regional economic ties. For them, in particular, it is beneficial to place part of their structures directly in the core of the agglomeration, and the other part on its periphery.

Small and medium-sized enterprises close to the, both included in the "first belt" of the agglomeration, and more remote, actively use its resources (wholesale centers, shopping malls, etc.) for their needs. Enterprises at its core, to a certain extent, are interested in the migration inflow, expanding the market demand for its goods and services. In turn, the absence of workers away from the core contributes to such an influx and excess population growth. At the same time, the ecological balance of spatial development can be achieved only in vast territories, since the existing dense development of the core of the agglomeration is unable to provide ecological balance and ecological requirements in the field of green areas, public spaces, and overall environmental quality.

A number of experts believe that at this stage the agglomeration process contributes to the development of production. Development business, retail and related industries are actively growing. There is also a relatively low involvement of business in the formation and implementation of the agenda on basic development issues. Entrepreneurs are "users" of the metropolitan area rather than actors. They are very limitedly represented in the sphere of public policy as such, and practically do not express their opinions on various aspects of the creation and implementation of an agglomeration project. 


\section{CONCLUSION}

According to expert opinion, a one-tier contractual model seems to be the most acceptable institutional solution for Krasnodar urban agglomeration. Let us note that this is what the municipal legislation of the Russian Federation postulates. However, in practice, more complex variations are possible, since the game involves a number of influential actors who often remain outside the scope of control system modeling. These include, first of all, a number of business structures in the construction industry with increased opportunities for lobby at the regional and local levels.

The interests of businesses from other spheres and industries are objectively related to the development of the agglomeration (both positively and negatively), but they are predominantly latent, weakly expressed. Being potential beneficiaries in the implementation of the project of systemic development of the agglomeration, for the most part, business structures at this stage do not act as an independent entity. This is largely due to the lack of mechanisms and institutional foundations that allow aggregating and articulating these interests according to sectoral, territorial and a number of other characteristics.

In general, the authors can argue that the controlled development of the agglomeration, the particularization of its institutional foundations will make it possible to more effectively structure investment entrepreneurial projects in accordance with territorial development projects, smooth out disproportions in spatial development, overcome the limited territorial resources, strengthen network interactions and significantly increase the attractiveness of the project for entrepreneurial structures.

Opportunities for increasing business involvement in the development of Krasnodar urban agglomeration are the following:

- active use of tools of municipal-private and public-private partnerships;

- introduction of additional measures to support small and medium-sized businesses, as well as a more detailed study of investment proposals;

- diversification of the investment portfolio due to the emergence of high-tech projects that are fundamentally new for the economy of the agglomeration;

- elaboration of mechanisms for attracting and supporting medium-sized investors in terms of the volume of attracted funds.

Since inclusiveness is currently becoming an important attribute of the comanagement system in the development of an agglomeration, the system of tasks facing the governing bodies requires constant adaptation to rapidly changing conditions in four main areas:

- adaptation of management processes to changes in the agglomeration development, decentralization, understanding the role of business participation and social integration, inclusive management;

- adaptation of the development strategy to the emerging challenges and interests of society, distribution of powers and analysis of the influence of stakeholders on the effectiveness of decisions made;

- determination of issues to be resolved in a collaborative manner, including using instruments of municipal-private and public-private partnerships;

- development of co-management tools in the areas of "smart" city, ESG factors, ecology and decarbonization, circular economy, infrastructure and implementation of information and communication technologies. 


\section{REFERENCES}

Connolly, C. (2020). From resilience to multi-species flourishing: (Re)imagining urban-environmental governance in Penang, Malaysia. Urban Studies, 57(7), 1485-1501. https://doi.org/10.1177/0042098018807573

Deng, F. (2018). Stakes, stakeholders and urban governance: a theoretical framework for the Chinese city. Eurasian Geography and Economics, 59(3-4), 291-313. https://doi.org/10.1080/15387216.2019.1570298

Edelendos, J., \& van Meerkerk I. (2018). Finding common ground in urban governance networks: what are its facilitating factors. Journal of Environmental Planning and Management, 61(12), 2094-2110. https://doi.org/10.1080/09640568.2017.1383232

Government of the Russian Federation (2019). Spatial development strategy of the Russian Federation for the period up to 2025 (in Russian). Retrieved from http://static.government.ru/media/files/UVAlqUtT08o60RktoOX122JjAe7irNxc.pdf

Korotkova, E., Mokrushina K., Kuricheva E., Zhuravlev S., Irbitskaya I. (2016). Management of the spatial and economic development of the city: hidden resources. - Moscow: Center for Urban Studies of Skolkovo Business School.

Krugman, P.R. (1991). Geography and Trade. Cambridge, MA: MIT Press.

Legislative Assembly of the Krasnodar Territory (2018). Strategy of socio-economic development of Krasnodar region until 2030 (In Russian). Retrieved from https://www.economy.gov.ru/material/file/e4e8b9ddede078a93f60f5e7a08fce28/krasnodar.pdf

Liming, C., Rana, H., \& Yi, J. (2021). Urban Agglomeration and Firm Innovation: Evidence from Asia. The World Bank Economic Review, lhab022. https://doi.org/10.1093/wber/lhab022

Marshall, A. (1984). Principles of Political Economy. V. II. M.: Progress.

Minakir, P.A. (2019). Russian Economic Space: Strategic Impasses. Economy of Region (Ekonomika regiona), 15(4), 967-980. https://doi.org/10.17059/2019-4-1

Mossberger, K., \& Stoker, G. (2001). The evolution of urban regime theory the challenge of conceptualization. Urban Affairs Review, 36(6), 835. https://doi.org/10.1177/10780870122185109

North, D. (2021). Economic Performance through Time. Retrieved on 11.10 .2021 from http://www.strana-oz.ru/2004/6/funkcionirovanie-ekonomiki-vo-vremeni

Peters, B.G., \& Pierre J. (2012). Urban Governance. The Oxford Handbook of Urban Politics.

Pierry, J. (1999). Models of urban governance: The institutional dimension of urban politics. Urban Affairs Review, 34(3), 372-396. https://doi.org/10.1177/10780879922183988

Puzanov, A., \& Popov, R. (2017). Approaches to assessing the development of urban agglomerations. Moscow: Institute of Urban Economics.

Stone, C.N. (1989). Regime politics: Governing Atlanta. University of Kansas Press.

Titov, E.A. (2021). Urban co-management: concept and modern research. Issues of state and municipal management, 1, 173-194.

The city Duma of Krasnodar (2021). Strategy of socio-economic development of the municipality of the city of Krasnodar until 2030 (in Russian). Retrieved from https://krd.ru/departamentekonomicheskogo-razvitiya-investitsiy-i-vneshnikh-svyazey/strategicheskoerazvitie/strategiya/podrazdel/

\section{AUTHORS' SHORT BIOGRAPHY}

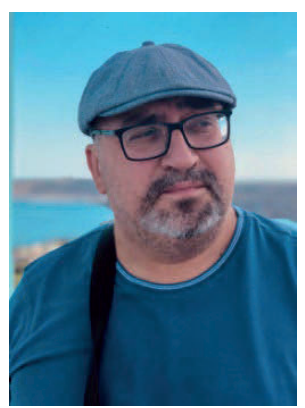

Alexey Kolba (Dr. sc. pol.) is a Professor, Department of Public Administration, Kuban State University, Krasnodar, Russia

Research interests: Political and Regional Conflictology, Urban Agglomerations Management Policy; Conflict Management.

E-mail: alivka2000@,mail.ru

ORCID: http://orcid.org/0000-0002-7663-8890 


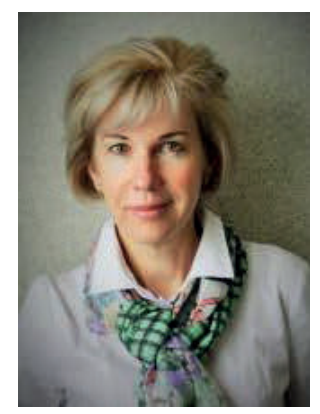

Maria Tereshina (Dr. oec.) is a Professor, Department of Public administration Kuban State University, Krasnodar, Russia

Research interests: Green and Circular Economy, Regional Sustainable Development, Urban Agglomerations Management; Regional Economy, Regional Innovative System.

E-mail: mwstepanova@mail.ru

ORCID: http://orcid.org/0000-0001-8982-5831 